Revista Facultad de Ingeniería

Journal Homepage: https://revistas.uptc.edu.co/index.php/ingenieria

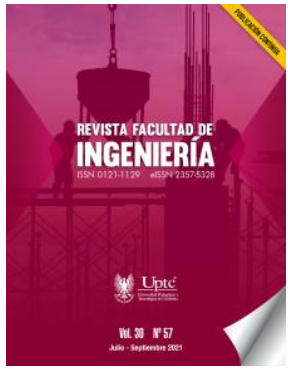

\title{
DevOps in Industry 4.0: A Systematic Mapping
}

\author{
Elizabeth Suescún-Monsalve ${ }^{1}$ \\ César-Jesús Pardo-Calvache ${ }^{2}$ \\ Sergio-Andrés Rojas-Muñoz ${ }^{3}$ \\ Alejandro Velásquez-Uribe ${ }^{4}$
}

Received: May 22, 2021

Accepted: July 03, 2021

Published: July 12, 2021

Citation: E. Suescún-Monsalve, C.-J. Pardo-Calvache, S.-A. Rojas-Muñoz, A. Velásquez-Uribe, "DevOps in Industry 4.0: A Systematic Mapping," Revista Facultad de Ingeniería, vol. 30 (57), e13314, 2021. https://doi.org/10.19053/01211129.v30.n57.2021.13314

\section{Abstract}

DevOps is the acronym for the integration of development and operations, which allows the improvement of communication and collaboration. Likewise, its objective is to help organizations develop software products and services quickly without sacrificing quality or cost. Additionally, its focus is on development, integration, delivery, release, testing, and continuous monitoring through the automation of tasks. Industry 4.0 solutions seek to digitize the industries' processes and services

\footnotetext{
${ }^{1}$ Ph.D. Universidad EAFIT (Medellín-Antioquía, Colombia). esuescu1@eafit.edu.co. ORCID: 0000-0001-7872$\underline{7638}$

$\frac{7638}{2}$ Ph. D. Universidad del Cauca (Popayán-Cauca, Colombia). cpardo@unicauca.edu.co. ORCID: 0000-00026907-2905

3 Universidad EAFIT (Medellín-Antioquía, Colombia). smunozr2@eafit.edu.co. ORCID: 0000-0002-2606-2539

${ }^{4}$ Universidad EAFIT (Medellín-Antioquía, Colombia). avelas61@eafit.edu.co. ORCID: 0000-0003-3358-894X
} 
to make them faster, safer, and more efficient through new technologies. These developments are not unrelated to the practices proposed by DevOps. This article presents a systematic mapping of the literature to identify the adoption prospects of DevOps practices for Industry 4.0 solutions reported in the literature. This work gathers proposals that show the importance and relevance of adopting DevOps to develop solutions for Industry 4.0. Organizations must prepare to address Industry 4.0 solutions; this will allow them to survive and prosper in the era of the Fourth Industrial Revolution. Therefore, it is necessary to conceptualize and adopt a solution development model that enables them to address these challenges and DevOps with its principles and standards, which would reduce operating costs and improve the service levels, efficiency, and administration of the different areas.

Keywords: agile development; DevOps and Industry 4.0; DevOps Industrial; industrial software; systematic mapping.

\section{DevOps en la industria 4.0: Un mapeo sistemático}

\section{Resumen}

DevOps es un acrónimo para integrar las áreas de desarrollo y operaciones que permite mejorar la comunicación y colaboración, asimismo, su objetivo es ayudar a las organizaciones a desarrollar productos y servicios software de forma rápida sin sacrificar calidad, a menor costo, con un enfoque de desarrollo, integración, entrega, liberación, pruebas y supervisión continua a través de la automatización de tareas. Las soluciones de Industria 4.0 buscan la digitalización de los procesos y servicios de las industrias para hacerlos más rápidos, seguros y eficientes a través de las nuevas tecnologías, dichos desarrollos no son ajenos a las prácticas propuestas por DevOps. Este artículo presenta un mapeo sistemático de la literatura que tiene como objetivo identificar las perspectivas de adopción de las prácticas DevOps para soluciones de la Industria 4.0 reportadas en la literatura. Este trabajo agrupa propuestas que evidencian la importancia y pertinencia de adoptar DevOps en desarrollos de soluciones para la Industria 4.0. Es fundamental que las organizaciones se preparen para abordar soluciones de la Industria 4.0, esto les 
permitirá sobrevivir y prosperar en la era de la Cuarta Revolución Industrial. Por tanto, se necesita la conceptualización y adopción de un modelo de desarrollo de soluciones que los habiliten para abordar estos desafíos y DevOps con sus principios y estándares permitiría reducir los costos de operación y mejorar los niveles de servicio, la eficiencia y la administración de las diferentes áreas.

Palabras clave: desarrollo ágil; DevOps Industrial; DevOps e Industria 4.0; mapeo sistemático; software industrial.

\section{DevOps na indústria 4.0: Um mapeamento sistemático}

\section{Resumo}

DevOps é um acrônimo que integra as áreas de desenvolvimento e operações, permitindo a melhora na comunicação e colaboração, além disso, seu objetivo é ajudar as organizações a desenvolver produtos e serviços de software rapidamente sem sacrificar a qualidade, a um menor custo, com foco no desenvolvimento, integração, lançamento, teste e monitoramento contínuo através da automatização de tarefas. As soluções da Industria 4.0 procuram a digitalização dos processos e serviços das indústrias para fazer que eles sejam mais rápidos, seguros e eficientes através as novas tecnologias, esses desenvolvimentos não estão alheios às práticas propostas pelo DevOps. O presente trabalho descreve um mapeamento sistemático da literatura que visa identificar as perspectivas de adopção das práticas DevOps para soluções da indústria 4.0. Porém, é essencial que as organizações estejam preparadas para abordar as soluções de Industria 4.0 e assim sobreviver e prosperar na era da Quarta Revolução Industrial. Por conseguinte, é necessário conceituar e adotar um modelo de desenvolvimento de soluções que Ihes permita abordar os desafios e DevOps com seus princípios, normatividade para assim reduzir os custos operacionais e melhorar os níveis de serviço, a eficiência e a administração das diferentes áreas.

Palavras-chave: desenvolvimento ágil; DevOps Industrial; DevOps e Industria 4.0; mapeamento sistemático; software industrial. 


\section{INTRODUCTION}

The software development process is a formal agreement for the construction of systems with the following stages: analysis, design, implementation, testing, putting into production, and maintenance [1]. Thus, a development product must go through these stages, from its conception and requirements to its obsolescence, after the transformations throughout its use history.

In the 90s, software development was characterized by imprecise and changing requirements, in which delivery times required greater speed. In this scenario, there was an attempt to implement classical methodologies and models [2,3]; however, these did not provide the expected results. Thus, demonstrating the inefficiency of these methodologies to provide an efficient response to this typology of software products [4]. In this context, agile approaches emerge as an alternative to traditional methods without compromising product quality, which iteratively focuses on software development, with changing requirements, rapid return on investment (ROI), deliveries functional in early stages, and high customer participation. Among them, we have: Scrum, Feature Driven Development, Test Driven Development, Extreme Programming [1], [5].

As software development processes have been improved, their automation has also begun to improve. This is how the DevOps concept appears, the combination of the words Development and Operations, which highlights the quality of products and services in correlation with technology to achieve virtualized environments, cloud technologies, greater automation, and tools for configuration management [6]. In addition to motivating collaborative work, communication and integration of people to enhance continuous delivery and software products easier to deliver and maintain through automation [13].

On the other hand [7], the term Industry 4.0 emerges as a reference to what is considered to be the fourth industrial revolution, a synergy of digitization and extreme interconnection of productive activities. In addition to this, the impact on society is described, which is not merely technological. The integration of production technologies and Information and Communication Technologies (ICT) in the form of 
cyber-physical production systems presents infinite possibilities and opportunities to change how the industry adds value. Furthermore, the notable increase in communication, processing, and interaction capabilities with the environment suggests new products, services, business models, needs, and challenges, which ultimately question how the solutions proposed in this context are designed, developed, and maintained.

Considering this, it is pertinent to relate the literature on DevOps and Industry 4.0. Such reflection can reveal opportunities to propose more efficient processes, lead to a notable increase in flexibility and agility, adaptability, speed in time to market, shorter delivery times, among others [8]. In this sense, the objective of this article is to show the results of a systematic mapping that presents an updated vision about the links, benefits, and possibilities of the adoption of DevOps in Industry 4.0 solutions reported in the literature.

The article is organized as follows: Section 2 describes the research protocol used to perform the systematic mapping. Section 3 contains the analysis of the results obtained in the mapping. Section 4 presents the main discussion and observations of the results and the limitations and implications of adopting DevOps in Industry 4.0 solutions. Finally, Section 5 presents the conclusions and recommendations for future works.

\section{Methodology}

A systematic mapping of the literature is a methodological process that allows collecting and categorizing existing information on a research topic. This systematic mapping was made following the guidelines presented in the following studies: [9,10 11,12 ]. The systematic mapping was carried out in three stages: (i) Planning, where the research questions, keywords, synonyms, and search strings, which led to the inclusion and exclusion criteria, were defined; (ii) Execution, and (iii) Documentation of the results. For space reasons, this process is not included in this article; however, it can be found in its entirety at https://n9.cl/7otaz for consultation or eventual replication. 


\section{RESULTS}

The contribution that each of the works made to the research questions proposed for this work (Selected Works in the following link: https://n9.cl/4lno3) can be consulted at https://n9.cl/pbktu. Also, the convention used to name the Selected Works will be an S for Study, followed by the consecutive number. Parentheses will be used to differentiate from the general references of this work.

\section{A. Question 1: What is the Current State of Implementation of DevOps Practices in Industry 4.0?}

According to the literature, there is a specific interest in the adoption of DevOps in Industry 4.0. Thirty-three percent of the works showed the benefits in the development of current software and its transfer to organizations in digital transformation processes or Industry 4.0 (S3, S7, S8, S9, S10, S11, S13, S15, and $S 16$ ). The maturity and learnings that the software industry has had in culture, agile frameworks, and the use of agile principles and practices is something that Industry 4.0 should not ignore. Both in (S11) and (S10), it is highlighted that Industry 4.0 needs an immediate adoption of new proposals for the implementation of solutions and forms of deployment. In (S11) and (S13), on the one hand, the cascade model in general manufacturing systems integration projects is analyzed, as well as DevOps adapted to this type of development. The first does not adjust to the new challenges, defiances, and modern solutions; the second proposes applying practices such as continuous deployment and rapid feedback.

The different enabling technological developments in Industry 4.0, such as blockchain, big data, and IoT, can be managed and implemented with DevOps, bringing benefits similar to those identified in the software industry. In addition, it can be gained in the generation mechanism of approach to all areas involved with the development and management of production, with the active participation of the company's different roles, developers, and stakeholders. Explicitly in (S7), it is said that in many organizations, the digital transformation is related to Industry 4.0. This work highlights that to address these new software development and delivery 
approaches, DevOps concepts such as agile development, product management, on-site reliability engineering, dynamic infrastructure and operations, continuous delivery, and teams that develop and deploy must be integrated into the software. This implies a shift from project management approaches to techniques and theories influenced by operations management, agility, industrial engineering, and organizational culture.

In (S8), it is said that automation and monitoring practices must be considered for the adoption of DevOps, which is based on agile thinking in the context of solutions for Industry 4.0. It also emphasizes breaking down the division of different roles and establishing a unified incident support team. In the same sense, in (S9), DevOps is presented as the latest Agile and Lean vision for the current management of operations and maintenance. It is the new mode of operation and maintenance proposed in new technologies such as cloud computing and automated operation, emphasizing automation and continuous operation and maintenance of everything. In this same work, it is proposed to break the segmentation between areas and their different functions to promote more cross-functional roles; for example, support engineers involved in the technical development process and developers involved in the operation and maintenance process and establish a unified support team.

As a whole, the article that contributed the most to answer this question was (S3). It explicitly addresses the concepts of DevOps for Industry 4.0 and practices such as the continuous process in operation, observation, and development. The work also describes how it is incorporated in industrial environments and presents the advantages or benefits that DevOps practices, methods, and culture would bring when integrated into industrial production environments, in which software is one of its components.

\section{B. Question 2: What are the Benefits of Implementing DevOps Practices in Industry 4.0?}

Seventy-four percent of the works reported benefits in the adoption of DevOps practices in Industry 4.0 Solutions (S3, S4, S5, S6, S7, S9, S10, S11, S14, S15, S16, 
$\mathrm{S} 18, \mathrm{~S} 20, \mathrm{~S} 21, \mathrm{~S} 22, \mathrm{~S} 23, \mathrm{~S} 24, \mathrm{~S} 25$, and S27), including automation practices, continuous process in operation, continuous observation and development, agile manufacturing, cloud manufacturing, collaborative manufacturing, on-site reliability engineering, dynamic infrastructure and operations, delivery continuous, software deployment in a short life cycle with continuous monitoring, communication between the development team, agile practices, Scrum, and Lean, among others. Furthermore, works like (S3, S4, and S7) confirmed that there is a change of thought when integrating DevOps in Industry 4.0; bringing notorious benefits such as processes with more flexibility to change due to continuous adaptation, the culture of iterative deliveries, continuous analysis and monitoring processes, early identification of requirements and in this way a continuous improvement of the product. Additionally, it was reported that when implementing DevOps, there is a motivation to have a high degree of automation in the processes, identifying what can be automated and what cannot, with particular emphasis on repetitive processes in companies to ensure the quality of these and in many cases their efficiency (S16 and S20). Also, with the implementation of DevOps in companies, a change in perspective was identified when producing a good or a service; it means that agile frameworks motivate the creation of value based on the user and constant feedback from clients or users so that things are correctly done (S17).

In (S22), an architecture proposal that offers a roadmap for companies with an Industry 4.0 approach using DevOps principles was developed. In this study, the authors claim that DevOps represents the latest agile, lean, and automation thinking advocated by today's O\&M management. Additionally, (S25) examines the implementation of DevOps in practice through an exploratory case study based on interviews with 11 industries and professionals from nine organizations. As a result, an empirical taxonomy of DevOps implementation is described, in which the interaction of developers with local operations, outsourced operations, DevOps teams, and DevOps bridge teams can work as a reference for Industry 4.0. In this same line of work is (S27), where infrastructure as code is described as a DevOps tactic to manage and provision infrastructure through machine-readable definition 
files instead of physical hardware configuration or interactive configuration tools and from a very pertinent maintenance and evolution perspective in Industry 4.0. Finally, in (S26), the reconsideration of the traditional models of an organization regarding its IT areas is proposed. It suggests that these should follow certain fundamental design principles, with minimal functionality and fewer dependencies, portability, shared knowledge, predictable contracts, and maximized human value. According to its authors, the last three points encapsulate the very definition of DevOps. In the end, this work presents through a case the valuable lessons learned from the mistakes in the adoption of DevOps.

\section{Question 3: What is the Proposed Adoption of DevOps Practices in Industry}

\section{0?}

Of the studies analyzed, $81 \%$ (S1, S2, S3, S5, S6, S7, S8, S9, S12, S13, S14, S17, $\mathrm{S} 18, \mathrm{~S} 19, \mathrm{~S} 20, \mathrm{~S} 21, \mathrm{~S} 22, \mathrm{~S} 23, \mathrm{~S} 24, \mathrm{~S} 25, \mathrm{~S} 26$, and S27) propose or describe DevOps practices that could be effective in companies with a vision of Industry 4.0; however, it is pointed out that it will depend a lot on the sector and the type of operations and developments that the company has; and although they are different adoption frameworks, it is possible to identify some similarities between them. In this context, we want to highlight that the implementation of DevOps implies a change at a cultural level in the company; this is one of the strongest barriers, especially when there are highly static processes or tasks that have been pre-established for a long time (S4 and S26). Likewise, people should be motivated to think that there may be a better way to get things done, improve the process or develop within the company to obtain a greater benefit. Additionally, having a continuous delivery of value, agile development, product management, reliability engineering on site, infrastructure and dynamic operations, continuous delivery, and teams that develop and deploy software in a short life cycle, with execution and resource management is also vital. This implies a change from project management approaches to techniques and theories influenced by operations management, agility, industrial engineering, and organizational culture (S7). 
In (S2), it is shown that automation practices can be valuable for Industry 4.0 and DevOps solutions. In (S18), DevOps practices in the Scrum framework could work as a mechanism that allows a rapid response to the needs in Industry 4.0. In addition, it proposes that, under this approach, the advantages of the combination of operations and development should be used. Also, they affirm that DevOps in software development is an appropriate framework to improve software quality during its life cycle; it is shown how this methodology would be used in the context of Industry 4.0. In (S21), a route is proposed to design solution architectures for Industry 4.0 considering the stages of the software development life cycle, using agile approaches. In this work, a framework structured in three phases within the life cycle is proposed: the first one for the creation of user stories or requirements; the second for the planning of the cycles; and finally, increment delivery that can be functional software or value generation. Additionally, the continuous integration generally associated with the delivery phase and DevOps practices should be considered.

The proposal described in (S6) focuses on presenting incident management in the context of Industry 4.0, at the same time describing it as an interconnection and automation mechanism that must have a large number of devices in the system, the systems development complex, and in different regions and organizations, where all these elements require good management. Regarding the incidents to be solved, it is said that these can involve different departments and even organizations, as well as technical personnel, operational and maintenance. According to the authors, it is recommended that the operation and maintenance processes are efficient when implementing a large-scale system. Therefore, it is necessary to consider the agile and lean thinking of DevOps and use automation and cloud computing tools and other technologies to achieve automated incident processing and establish a unified system. In (S19), case studies of companies that carried out digital transformation processes and processes for Industry 4.0 are presented. Success and failure cases are described. As a general observation, DevOps was identified as an agile framework that can support the required development paths and a mechanism for 
learning from mistakes, managing complexity, and technical possibilities. In addition, it is vital to identify which enabling technologies for Industry 4.0 are wanted to be implemented, as well as the processes and tasks that can be automated. Likewise, it is needed to measure the organization's capabilities and cost; in short, be realistic with the adoption of DevOps (S5). This work presents a literature review that identifies preparation models for Industry 4.0; it proposes dimensions such as technology, people, strategy, leadership, processes, and innovation. This work also highlights organizations' strengthening and technological preparation and the evaluation of technological capabilities as the most critical dimensions.

\section{Question 4: What Types of Software or Application Solutions Support the} Adoption of DevOps Practices in Industry 4.0?

The tools used in the software development life cycle can be considered in Industry 4.0 management environments. Thirty-seven percent of the selected works describe it that way (S2, S3, S4, S8, S12, S13, S15, S16, S17, and S19). It should be noted that many of the systems that are currently used in this context focus on collecting data from both the physical and digital environment with diverse technologies: industrial loT devices, robotic tools, autonomous robots, Big Data systems, digital twins that collect and analyze large amounts of data, artificial intelligence systems, cognitive systems and systems that implement augmented reality; all of which requires understanding other requirements beyond technologies. For example, connectivity, interoperability, and an understanding of data, some for making decisions in real-time and others in the medium and long term (S3, S15, S16, S17, and S20). Therefore, the entire production and value chain must be analyzed to find a way to integrate DevOps and the technologies that support it in the product life cycle, and in the case of Industry 4.0, to generate a synergy between production and development of systems.

In (S15), the authors claim that IT is fundamental for innovation in almost any industry, and those that are used correctly and effectively will have a significant leadership position; otherwise, they will not be able to survive. The authors of this 
work illustrate Blockchain technology as an enabler of Industry 4.0. This research suggests that this will play a fundamental role in the digital transformation of industries and applications in general. It will allow secure trust frameworks, generate an agile value chain production and a closer integration with technologies, including cloud computing and the IoT. With a case study, the researchers demonstrated the ability to apply engineering principles, combined with a DevOps approach to development and iterative management and integration of security. Other works that present an enabler of Industry 4.0 are (S16) and (S20 in which it is stated that the manufacture of products must respond to greater optimization to satisfy the needs of the global market.

Consequently, an agile, dynamic production process that allows competitiveness will be required. Responding to the need for digitization of factories, an example of such digitization is the digital twin. These works describe the implementation of a digital twin and how it can even be an enabler for DevOps applications in cyber-physical production systems. According to the authors, DevOps aims to merge development and operations to provide a continuous and agile process; the production process can be fully integrated and automated with continuous improvement since a digital twin improves flexibility due to its adaptability and perfect interaction between the physical system and its virtual model. In short, DevOps is relevant in the process of implementing this type of system. Plus, it closes the gap between development and operations throughout the entire product lifecycle. Another enabling technology is the industrial big data analysis shown in (S17) and (S3). In (S17) specifically, the adoption of DevOps is presented to allow adaptation and continuous improvement in industrial manufacturing by making industrial data available to stakeholders; this, given that trends towards smart manufacturing, cyber-physical production systems, and Industry 4.0 result in a large number of industrial internet of things (IOT) sensors and data to be managed. Finally, in (S3), a software platform called Titan is presented, accompanied by a model that incorporates industrial production environments with DevOps, which can integrate different types of sensors that use data schemas, formats, and protocols in addition to what allows infrastructure 
monitoring. Two case studies were presented to show the tool's utility, and, as a case study, it was possible to obtain detailed information on energy usage and its potential savings.

\section{Discussion}

Industry 4.0 is significant for all that it integrates. It entails the current digital transformation of the production system and is based on the integration of information technologies, communications and industrial technology, and is mainly dependent on the information-based software system construction. Consequently, the basis of Industry 4.0 will be to build highly flexible manufacturing systems, with a better service, in less time, of better quality and with greater safety for its target audience. Also, the manufacturing process needs to be highly enabled through the use of information technologies. Additionally, from the software perspective, the following will be required: more frequent updates, functions, or versions of the product, maintaining the desired levels of quality and security, with real-time interactions between people or devices, people and teams that develop them, and people who consume services. DevOps is an approach that changes how software is developed; therefore, companies with an Industry 4.0 focus must adhere to this methodology.

In addition, some studies compared traditional methods used in current manufacturing projects, showing their poor adaptability, high investment and maintenance costs due to changing requirements and the challenges that Industry 4.0 solutions are bringing to organizations. In contrast, it can be said that it is necessary to implement DevOps practices in industrial environments and assimilate the benefits it has granted to the software industry in general. Similar to the movement generated in the software development industry, DevOps would change the way in which the development cycle is managed at a technological level but mainly at a cultural level. Development and operations teams would eliminate "in silos" work and start working in a collaborative, two-way fashion. The adoption of DevOps would allow a better adaptation and interpretation of the processes and give 
flexibility and the possibility of being adapted to the measure of each organization that wants to put it into practice, according to its structure, circumstances, capabilities, and production chain.

To indicate the scope of the present work, it is relevant to consider the threats to validity, listed below: (i) the search strings in the process could include inappropriate search terms related to the research topic; (ii) only the automatic search was applied, and (iii) we selected articles that included the words Industry 4.0 and DevOps solutions from the last five years. This situation can lead to bias in the identification of primary studies. Furthermore, since the topic of DevOps has been explored since 2008 and the digitization of industry since 2011, we do not guarantee that all related primary studies and adoption factors were selected; articles that could contribute may have been discarded. These threats to validity may affect the generalizability of the results of our literature review. To minimize these threats and avoid biases in the data extraction, the entire process was executed by cross-checking between the authors.

\section{ConcLusions}

This article presents a mapping of the literature that seeks to demonstrate the current state of the adoption of DevOps for Industry 4.0 solutions through dimensions, such as the benefit of implementing DevOps practices, the adoption proposals, and the type of solutions that are supporting the use of DevOps in Industry 4.0. The results obtained made it possible to reflect the profound relationship between industrial production environments and digitization for Industry 4.0. In this sense, it is necessary to transfer good practices in software development that have already shown positive results in the context of current solutions. Therefore, this is an excellent time to give visibility and introduce DevOps practices, methods, and culture in industrial production environments. The fundamental concept of this approach is a continuous process of operation, observation, and development of the entire production environment. In this way, all stakeholders, systems, and data can be integrated in incremental steps and quickly make adjustments. 
Likewise, this study showed the direction organizations are taking to digitize their processes and better adapt to what is already known as the 4th industrial revolution. It is in this context that some organizations have already confirmed the relevance of adopting DevOps as an effective convergence of the areas of the organizations, the benefits of rapid development, improved reliability, more effective market launch (time to market), early feedback, and forms of distribution contextualized to new challenges.

As future work, it is proposed to evaluate the principles, methods, structures and practices established in DevOps in different industrial application scenarios. Also, it is expected to review the failed DevOps literature and do a comparative analysis with those industries that are already using its adoption for Industry 4.0 solutions.

\section{ACKNOWLEDGMENT}

Professors PhD. Elizabeth Suescún and PhD. César Pardo appreciates the contribution of EAFIT University (Medellín) and the University of Cauca (Popayán), where they currently work as Assistant Professor and Associate Professor correspondingly.

\section{AUTHORS' CONTRIBUTION}

Elizabeth Suescún-Monsalve: Supervision, investigation, writing - revision and edition.

César-Jesús Pardo-Calvache: Supervision, investigation, writing - revision and edition.

Sergio-Andrés Rojas-Muñoz: Methodology, design, validation, writing - original draft.

Alejandro Velásquez-Uribe: Methodology, design, validation, writing - original draft. 


\section{REFERENCES}

[1] L. Garcés, L. Egas, "Evolución de las Metodologías de Desarrollo de la Ingeniería de Software en el Proceso de la Ingeniería de Sistemas," Revista Científica y Tecnológica UPSE, vol. 1, no. 3, e29, 2013 https://doi.org/10.26423/rctu.v1i3.29

[2] J. Gamboa, "Evolución de las Metodologías y Modelos utilizados en el Desarrollo de Software," INNOVA Research Journal, vol. 3, no. 10, pp. 20-33, 2018

[3] A. Cadavid, J. Martínez, J. Vélez, "Revisión de metodologías ágiles para el desarrollo de software," Prospectiva", vol. 11, no. 2, pp. 30-39, 2013

[4] O. Pérez, "Cuatro enfoques metodológicos para el desarrollo de Software RUP - MSF - XP - SCRUM," Revista Inventum, no. 10, pp. 64-78, 2011. https://doi.org/10.26620/uniminuto.inventum.6.10.2011.64-78

[5] E. Uribe, L. Ayala, "Del manifiesto ágil sus valores y principios," Scientia et technica, vol. 13 no. 34, pp. 381-386, 2007

[6] J. Humble, G. Kim, Accelerate: The science of lean software and devops: Building and scaling high performing technology organizations, IT Revolution, 2018.

[7] M. Navarro, X. Sabalza, "Reflexiones sobre la Industria 4.0 desde el caso vasco," Ekonomiaz: Revista vasca de economía, no. 89, pp. 142-173, 2016

[8] G. Kim, J. Humble, P. Debois, J. Willis, The DevOps Handbook: How to Create World-Class Agility, Reliability, and Security in Technology Organizations,. IT Revolution, 2016.

[9] K. Petersen, R. Feldt, S. Mujtaba, M. Mattsson, "Systematic mapping studies in software engineering," in 12th International Conference on Evaluation and Assessment in Software Engineering (EASE), 2008, pp. 1-10. https://doi.org/10.14236/ewic/EASE2008.8

[10] B. Kitchenham, "Systematic review in software engineering: where we are and where we should be going," in Proceedings of the 2nd international workshop on Evidential assessment of software technologies, 2012, pp. 1-2. https://doi.org/10.1145/2372233.2372235

[11] D. Budgen, M. Turner, P. Brereton, B. Kitchenham, "Using Mapping Studies in Software Engineering," in Proceedings of PPIG 2008, 2008, pp. 195-204.

[12] M. Petticrew, H. Roberts, Systematic Reviews in the Social Sciences: A Practical Guide, Malden, USA: Blackwell Publishing. https://doi.org/10.1177/00380385080420051403

[13] R. Jabbari, N. Bin, K. Petersen, B. Tanveer, "What is DevOps?," in PXP '16 Workshops: Scientific, 2016, pp. 1-11.

Revista Facultad de Ingeniería (Rev. Fac. Ing.) Vol. 30 (57), e13314. July-September 2021. Tunja-Boyacá, Colombia. L-ISSN: 0121-1129, e-ISSN: 2357-5328. 